NBER WORKING PAPER SERIES

INFORMAL CENTRAL BANK COMMUNICATION

Annette Vissing-Jorgensen

Working Paper 28276

http://www.nber.org/papers/w28276

\author{
NATIONAL BUREAU OF ECONOMIC RESEARCH \\ 1050 Massachusetts Avenue \\ Cambridge, MA 02138 \\ December 2020
}

I thank Adair Morse for many productive discussions. The views expressed herein are those of the author and do not necessarily reflect the views of the National Bureau of Economic Research.

NBER working papers are circulated for discussion and comment purposes. They have not been peer-reviewed or been subject to the review by the NBER Board of Directors that accompanies official NBER publications.

(C) 2020 by Annette Vissing-Jorgensen. All rights reserved. Short sections of text, not to exceed two paragraphs, may be quoted without explicit permission provided that full credit, including () notice, is given to the source. 
Informal Central Bank Communication

Annette Vissing-Jorgensen

NBER Working Paper No. 28276

December 2020

JEL No. E5,G12

\begin{abstract}
$\underline{\text { ABSTRACT }}$
Starting from a set of facts on the timing of stock returns relative to Federal Reserve decisionmaking, I argue that informal communication - including unattributed communication -- plays a central role in monetary policy communication. This contrasts with the standard communications framework in which communication should be public and on-the-record because it serves to ensure accountability and policy effectiveness. I lay out possible benefits of using unattributed communication as an institution, but these should be weighed against substantial costs: It runs counter to accountability to use unattributed communication, causes frustration among those trying to understand central bank intensions, and enables use of such communication by individual policymakers. Unattributed communication driven by policymaker disagreements is unambiguously welfare reducing, because it reduces policy flexibility and harms the central bank's credibility and decision-making process. Central banks may benefit from resisting unattributed communication via expensive newsletters and increasing consensus-building efforts to reduce disagreement-driven unattributed communication.
\end{abstract}

Annette Vissing-Jorgensen

Haas School of Business

University of California, Berkeley

545 Student Services Building, \#1900

Berkeley, CA 94720

and NBER

vissing@haas.berkeley.edu 


\title{
Informal Central Bank Communication
}

\author{
By Annette Vissing-Jorgensen ${ }^{1}$
}

\begin{abstract}
Starting from a set of facts on the timing of stock returns relative to Federal Reserve decision-making, I argue that informal communication - including unattributed communication -- plays a central role in monetary policy communication. This contrasts with the standard communications framework in which communication should be public and on-the-record because it serves to ensure accountability and policy effectiveness. I lay out possible benefits of using unattributed communication as an institution, but these should be weighed against substantial costs: It runs counter to accountability to use unattributed communication, causes frustration among those trying to understand central bank intensions, and enables use of such communication by individual policymakers. Unattributed communication driven by policymaker disagreements is unambiguously welfare reducing, because it reduces policy flexibility and harms the central bank's credibility and decision-making process. Central banks may benefit from resisting unattributed communication via expensive newsletters and increasing consensus-building efforts to reduce disagreement-driven unattributed communication.
\end{abstract}

\section{Facts: Information flows at unexpected times}

I want to start with a set of facts to argue that central bank communication does not always work the way you may think. The facts are about the Federal Reserve but, as you will see, a lot of the underlying economics generalizes to the ECB context.

Fact 1. Based on data from 1994 to 2011, Lucca and Moench (2015) document that the average US stock return in the 24-hour period from $2 \mathrm{pm}$ to $2 \mathrm{pm}$ prior to scheduled FOMC announcements was about 50 bps. They view this as a puzzle since monetary policy news coming out would have to be systematically positive and leaks are "unrealistic from an institutional viewpoint".

Fact 2. Studying stock returns over the full cycle between scheduled FOMC meetings, Cieslak, Morse and Vissing-Jorgensen (2019, CMVJ) document using 1994-2016 data that stock returns (in excess of T-bill returns) on days that fall in even weeks relative to the FOMC announcement day are on average 12 bps higher than stock returns on days that fall in odd weeks. Figure 1 a below illustrates this, plotting 5-day average excess returns for days $t$ to $t+4$ over the FOMC cycle. CMVJ argue that this pattern is driven by monetary policy news, which over the post-1994 period has been unexpectedly accommodating (as opposed to generating a risk

1 University of California Berkeley, CEPR and NBER. 
premium). To link the stock return pattern to monetary policy, they document that prior to 1994, when intermeeting target changes were common and thus reveal timing of Fed decision making/debate, these changes disproportionately took place in even weeks in FOMC cycle time. This is shown in Figure $1 \mathrm{~b}$ below. ${ }^{2} \mathrm{CMVJ}$ also show that Fed funds futures yields on average fell in even weeks in FOMC cycle time and that even-week stock returns were particularly high following low prior stock returns, consistent with a surprisingly strong "Fed put". They suggest that the evenweek timing of Fed news may arise from meetings/calls to discuss the discount rate requests from the Federal Reserve Banks. These requests are themselves a channel for influencing the target chosen at the next policy meeting. Each Reserve Bank has to submit a request at least every two weeks, implying that a two-week cycle for internal policy debate would be meaningful.

\section{Figure 1a}

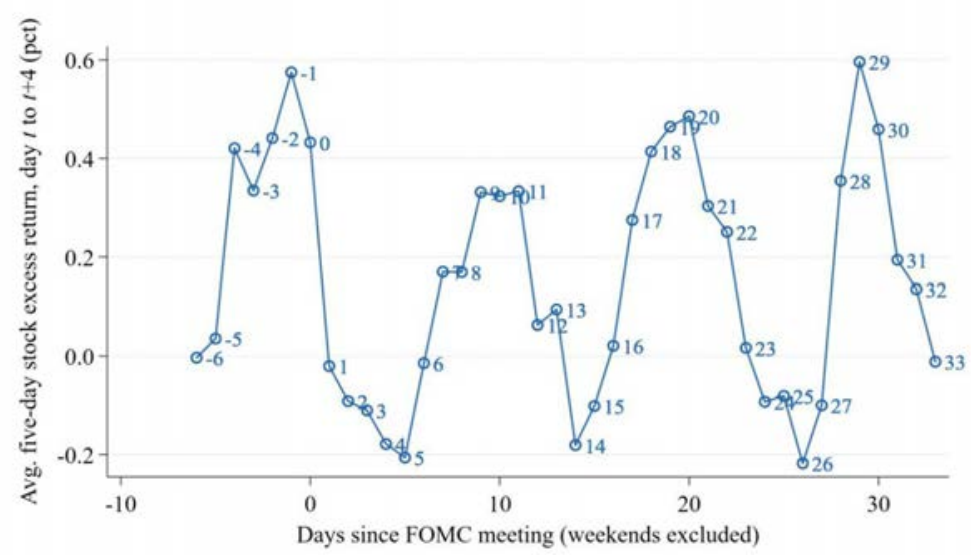

Figure 1b

Target changes over the FOMC cycle 1982M9-1993M12

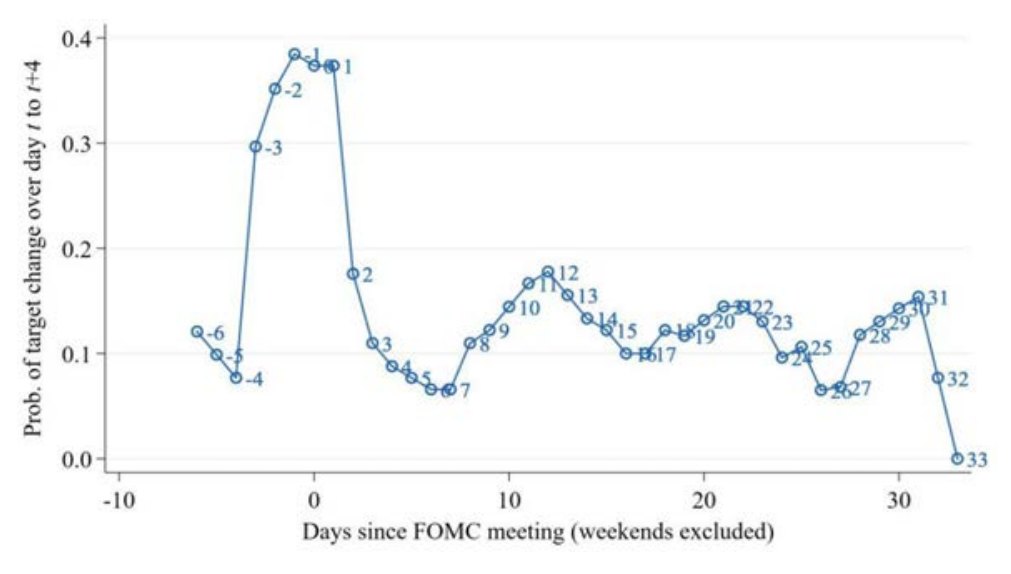

\footnotetext{
2 The peaks in Figure 1b are delayed a couple of days relative to the peaks in Figure 1a. Prior to 1994, the FOMC did not make an announcement after the target was changed. The data source used in CMVJ dates target changes based on when they were likely implemented in open market operations 1-2 days after the decision.
} 
Fact 3. Morse and Vissing-Jorgensen (2020, MVJ) study detailed calendars of a set of Federal Reserve governors from 2007-2018. They document that even-week returns are particularly high on days with interactions between governors and Reserve Bank presidents, either at FOMC events or in phone calls or meetings. Even-week days with governor-president calls/meetings see average stock returns that are 15 bps higher than other even-week days. This implies that the pre-FOMC period studied by Lucca and Moench (2015) is not special - even-week interactions among top policymakers appear to more generally be associated with information flow to markets. To document information flow via informal channels, MVJ document that average stock returns on even-week days with governor-president interactions are particularly high if there is informal communication via on-the-record public commentary by the FOMC (using data from FOMC Speak) or governor calendars list media interviews (of which almost none identifies the news outlet, suggesting they are not on-the-record).

What is surprising about these stock return facts is that they are unaffected by controlling for formal Fed communication: There are no formal communications during the pre-FOMC period as it is part of the blackout period, and CMVJ and MVJ find that controlling for speeches and formal information releases (e.g. Fed minutes) does not materially affect the results. This suggests that monetary policy news reaches markets via more informal channels.

Several pieces of evidence suggest a substantial role for unattributed communication: ${ }^{3}$

- CMVJ provide a series of examples of how confidential information from the Fed has appeared in newspapers or market newsletters. They discuss how the FOMC statement resulted from congressional pressure for transparency following a series of newspaper stories revealing confidential Fed information.

- $\quad$ Former Governor Meyer's 2004 book state: "The use of reporters as part of the Fed's signal corp is not official Board or FOMC doctrine. The public affairs staff and the Chairman like to pretend it doesn't happen."

- Greg Ip, a top reporter covering the Fed for the Wall Street Journal and the Economist, was asked in a 2012 interview whether he does a lot of "onbackground" interviews. He replied: "Yes, I do tons of them. With the Federal Reserve, for example, it's always been that way." 4

\footnotetext{
${ }^{3} \mathrm{~A}$ multitude of terms used in journalism to describe how information can be used by the reporter. "On-therecord" means that everything is usable and the source can be quoted by name. "Off-the-record" means the information obtained cannot be used for publication. In between there is a range of categories for which definitions vary. Using the Fed's interpretation, based on Meyer (2004), "not for attribution" means everything is usable, the source should not be directly identified, but the information can be attributed to "senior Fed officials" or the like. "On background" means information gathered can be used but not attributed to the official directly or the Federal Reserve but to "government officials" or similar. "On deep background" implies that information is usable but no source information should be given. I will use "unattributed" to refer to "not for attribution", "on background" and "on deep background".

${ }^{4}$ https://journalistsresource.org/tip-sheets/research/chat-the-economists-greg-ip-key-tips-businessreporting-analysis/
} 
- A comment by President Plosser at the January 2011 FOMC meeting is also informative: "My impression is that the Board, for example, gives very few onthe-record interviews, and, instead, the discussion is oftentimes on background."

This evidence begs the question of whether the transmission of monetary policy news via unattributed communication is how monetary policy communication is supposed to work.

\section{The traditional view of monetary policy communication}

Monetary policy is typically delegated to a central bank with some level of independence from elected politicians. This is done to ensure that the central bank is able to implement policy that may be unpopular but necessary, like raising rates or imposing macro-prudential rules. ${ }^{5}$ Furthermore, the complexity of central banking makes it a governmental function best delegated to an agency of experts. The role of communication in this setting is twofold.

Accountability, to sustain independence: A central bank needs to convey the gist of its deliberations to elected parliamentarians and the public so they can oversee that decisions are made competently in accordance with the central bank's mandate. Some of this communication invariably is technical in nature. However, the central bank's independence from political pressure is more likely to endure if the broad public understands decisions and views the central bank as competent.

Policy effectiveness: The impact of forward guidance and asset purchases on medium and long interest rates depends crucially on the public understanding the likely duration of low rates/monthly purchases. Furthermore, effective monetary policy requires economic agents (households, firms, governments) to understand the central bank reaction function. For example, agents will behave less conservatively in their spending decisions $(\mathrm{C}, \mathrm{I}$, or $\mathrm{G})$ if they understand that the central bank will accommodate aggressively if needed.

\section{On-the-record versus unattributed communication}

The traditional roles for communication suggest that communication should be public and on-the-record, conveying the central bank's chosen policy and policy framework, and allowing oversight by all who want to hold the central bank accountable.

\footnotetext{
${ }^{5}$ Bernanke (2015) describes the unpopularity of the AIG bailout and states: "If we acted, nobody would thank us. But if we did not act, who would? Making politically unpopular decisions for the long-run benefit of the country is the reason the Fed exists as a politically independent central bank. It was created for precisely this purpose: to do what must be done - what others cannot or will not do." The AIG example documents that even expansionary policies can be widely unpopular.
} 
Possible explanations for why unattributed communication plays a role can be grouped into two categories: ${ }^{6}$

1. The Federal Reserve as an institution may prefer unattributed to on-the-record communication in some situations

2. Unattributed communication could be driven by disagreeing policymakers who each try to influence the expectations of the public or financial markets in order to strengthen their bargaining position at the Fed.

Let me consider each possibility in turn.

\subsection{Benefits of unattributed institutional communication}

The political science literature is at the forefront of knowledge about unattributed communication since such practices are standard in politics. Pozen (2013) focuses on leaks from the White House and argues that many of these are not leaks in the sense of unauthorized disclosure but instead authorized "plants" of information in media outlets. Use of plants rather than for-attribution disclosure allows the sender to "impart information about executive branch policies without officially acknowledging those policies and thereby inviting unwanted forms of accountability or constraints". Mapping this to the central banking context, the benefits of unattributed communication include the following.

Flexibility: In the Fed context, it is beneficial to provide frequent policy guidance in order to facilitate more accurate decision making by the private sector. However, communication ties policymakers' hands if the public does not fully understand the state-contingent nature of policy. In that case, the Fed will be viewed as flip-flopping if policy differs from prior statements of likely outcomes. Unattributed comments may impose less of a constraint on subsequent policy decisions than on-the-record communication (since less of a promise has been made), though of course more than no communication at all.

Consistent with the idea that the Fed is very concerned about policy flexibility and views formal disclosure as especially flexibility-reducing, the Fed used to delay the release of minutes until after the subsequent FOMC meeting in order to "safeguard the Committee's flexibility to make needed adjustments to policy" (Vice Chairman Kohn, July 1993 FOMC meeting). Furthermore, in 1994 the Fed agreed to make public statements if policy is changed. This action coincided with an abrupt reduction in the frequency of intermeeting rate changes, from about $2 / 3$ to around $10 \%$ of all changes (see CMVJ). This has to my knowledge never been explained but is likely

\footnotetext{
${ }^{6} \mathrm{I}$ am disregarding the possibility that the documented return patterns are due to policymakers inadvertently disclosing large amounts of information, given the pervasive nature of information flow implied by the asset pricing evidence reviewed. I am also not going to discuss the very unlikely possibility that someone inside the Fed with access to the information is systematically trading on it.
} 
due to an aversion to make formal public statements for fear that they will tie the committee's hands going forward (in particular, by making it hard to reverse an intermeeting change for fear of looking less competent). Vissing-Jorgensen (2019) provides quotes from the FOMC transcripts to further document the importance of policy flexibility and how it is reduced by Fed disclosure.

Explaining: Use of unattributed communication could also be motivated by a Fed desire to explain its assessment of the economy and its policy or policy framework. Using background conversations with reporters is less time-consuming than on-therecord communication since it does not require the Fed to engage in a subsequent public debate about the information disclosed.

Learning: Another possibility is that unattributed communication via "plants" is used for learning purposes: to gauge support outside the Fed for a particular policy change (or economic assessment). This is what the political scientists refer to as a "trial balloon leak". By floating an idea not-for-attribution, the Fed avoids looking bad if the idea is unpopular and not implemented. A Wall Street Journal article discusses how Bernanke appears to have floated the idea of doing Operation Twist with a market newsletter in August 2011 to test the waters. ${ }^{7}$

These are all meaningful benefits, but unattributed communication has costs.

\subsection{Costs of unattributed institutional communication}

\section{Unattributed communication is the opposite of transparency and}

accountability: In a time of populism, a public appreciation for the role and tools of central banks is crucial for these to retain their legitimacy and independence. The Bank of England's Citizens' Panels, the "Fed Listens" events, and the "ECB Listens" events that are part of the ECB's review exemplify recent initiatives to increase transparency and accountability by engaging in direct communication with the public at large. Yet, the lack of public understanding of Federal Reserve informal communication stands in stark contrast to such efforts. I wonder what the newlyengaged citizens would think if we told them that the Federal Reserve, and perhaps other central banks, does a lot of its communication in ways that are not well understood but appears to have enormous impact on asset prices. I suspect they would worry about who gets access to all that information first and how their pension fund managers are doing in that race. Certainly, their trust in central banks as institutions would not increase. ${ }^{8}$

\footnotetext{
${ }^{7}$ https://www.wsj.com/articles/SB10001424052970204554204577025922155198762

${ }^{8}$ A quote by Mr Fisher, Manager of the Fed's System Open Market Account, summarizes his frustration with the Fed's communication giving unfair information access to some. Referring to market movements in the intermeeting period leading up to the June 1999 FOMC meeting, he states: "In my judgment, if you had tried to trade in the bond market during this period and had followed only the FOMC's announcement on May 18, the data releases as they came out, and the Chairman's Joint Economic Committee testimony, you would have lost a lot of money. On the other hand, if you had subscribed to all the high-priced insider rags and carefully tracked the utterances, attributed and unattributed, of FOMC members, you would have fared a good bit better."
} 
Frustration: It is likely that the level of frustration with Fed communication is higher if market participants are in a constant struggle to understand which newsletters and newspapers have obtained new information from the Fed. Is the Fed putting itself in a situation in which thousands of frustrated market participants and reporters are ready to criticize the Fed following any decision or announcement that appears inconsistent with prior perceptions $?^{9}$ In this sense, using unattributed communication may actually reduce policy flexibility, relative to on-the-record communication. Use it sparingly! It may come back to haunt you.

One could formalize this possibility as follows. Think of a setting in which today is date 0 (say half way through the policy cycle) and the central bank's next policy meeting is at date 1 . Express the credibility cost to the Fed of setting a policy rate $r_{1}$ at date 1 that differs from what the market expects after any date 0 disclosure as:

$$
\beta \times\left[r_{1}-E_{0}\left(r_{1}\right)\right]^{2}
$$

where

$$
\beta=\frac{[\text { Formality of date } 0 \text { disclosure }]+[\text { Frustration with Fed communication }]}{\text { Understanding of reaction function }}
$$

If the public has a complete (infinite) understanding of the Fed's reaction function, market expectations do not constrain policy -- $\beta$ is zero since the public will understand that news arrived between date 0 and 1 that necessitates a different policy rate. If not, communication matters. The flexibility argument is that less formal announcements retain more flexibility, here captured by [Formality of date 0 disclosure] and thus $\beta$ being lower. However, this ignores any indirect effects of disclosure choice on the frustration term. Accounting for that, unattributed communication may retain less flexibility than on-the-record communication.

Facilitates use by individual policymakers: By using unattributed communication as an institution, the Fed opens itself up more to the tug-of-war over market expectations by disagreeing policymakers. With less clear institutional guidance on how the consensus is evolving, individual policymakers have more room to try to drive market expectations.

\section{Individual policymaker use of unattributed communication}

Rather than it being used for institutional communication, the second possible driver of unattributed communication is that individual policymakers seek to gain influence from using it. Disagreement about appropriate policy is a central feature of group decision making and it places monetary policy making in a more standard political setting. Central bank communication in a setting with disagreement is not only

\footnotetext{
${ }^{9}$ We can argue about whether off-the-record communication enhances the understanding of the reaction function relative to on-the-record communication. Perhaps policymakers are willing to say more about the reaction function when they can use informal communication though a confident central banker should be happy to speak on-the-record.
} 
institutional but also individual. It becomes about affecting markets and public opinion to improve your bargaining position in policy negotiations.

\section{$5.1 \quad$ Individual communication}

An individual policymaker may seek to gain from changing public views in several ways.

Posturing: Making firm statements of what policy the policymaker prefers. This imposes a greater loss from compromise on the policymaker him/herself, thus improving his/her bargaining position. Posturing is clearly best done via public onthe-record communication, in speeches or interviews.

Influencing: Changing the public's view of appropriate policy by putting forward arguments supporting the policymaker's view. This makes it costlier for other policymakers to deviate from the policymaker's preferred policy.

Spin: Distorting the public's assessment of what the likely policy decision is. Those succeeding in moving the public's expectations in their preferred direction gain bargaining position because the central bank as an institution (and thus all central bank policymakers) suffer if the central bank is perceived as flip-flopping. Any perceived lack of competence plays into the hands of politicians seeking to reduce central bank independence.

The line between influencing and spin is thin. Both are intended to affect beliefs, but spin implies a use of more manipulative tactics to control the message. Crucially, if influencing or spin is based on confidential information, it has to be done using unattributed communication. In central banking, staff economic projections, internal deliberations, and views of colleagues are often confidential until a decision has been made (or in some cases much longer). ${ }^{10} 11$

In Vissing-Jorgensen (2019) I model the unattributed tug-of-war over market expectations between disagreeing policymakers, what one could call the "quiet cacophony". In the model, two policymakers set policy.

- $\quad$ Each policymaker's preferred policy rate evolves over time. Policymakers know each other's preferred rate at each point in time. They choose what to reveal to the public about policy preferences at an intermediate date between policy meetings. Policymakers care about how close the chosen policy rate is to their preferred rate but also about the central bank not being viewed as "flip-

\footnotetext{
10 The FOMC Policy on External Communications of Committee Participants lays out what is confidential, see https://www.federalreserve.gov/monetarypolicy/files/FOMC_ExtCommunicationParticipants.pdf

11 There are also instances where the identity of the messenger affects the impact of the message. For example, hearing that a known policy hawk thinks inflation is just around the corner may affect public opinion less than a press article stating that some central bank officials privately worry about the risk of inflation.
} 
flopping". If either policymaker communicates with the public, both incur a loss if the chosen policy rate deviates from the average preferred policy rate communicated at the intermediate date. Providing information at the intermediate date about policymaker preferences thus reduces policy flexibility.

- If no information is provided to the public, the chosen policy rate at the next meeting is the average of policymakers' preferred rates at that time.

- With communication, the chosen policy rate is a weighted average of the average preferred policy rate at the time of the meeting and the market's expectation of the average preferred policy rate based on information communicated at the intermediate date.

Given all this, will policymakers decide to disclose information about policy preferences at the intermediate date and what will they disclose?

- Assume that policymakers are to some extent able to spin market perceptions of policy preferences by selectively revealing internal information that supports a claim that policymakers' average preferred policy rate is higher (or lower) than is in fact the case.

The outcome of the game is that if disagreement is sufficiently strong (judged relative to the amount of news that may arrive before the next policy meeting) and sufficient spin is possible, the unique Nash equilibrium is that each policymaker communicates with his/her preferred spin in order to move the policy rate chosen in his/her preferred direction.

Figure 2 below illustrates how each policymaker's spin reacts to that of the opponent. In the example graphed, person D's preferred policy rate is lower than that of person $\mathrm{H}$. If $\mathrm{H}$ does not spin, $\mathrm{D}$ therefore spins the market's expectation of the average preferred policy rate negatively (point $\mathrm{A}$ in the figure). If $\mathrm{H}$ does spin, he will spin positively given his policy preference. The more positively $\mathrm{H}$ spins, the more negatively $D$ spins to counter. In equilibrium, we thus end up at point $B$ where both spin to the fullest extent possible $\left(S^{*}\right.$ and $\left.-S^{\star}\right)$ but the spin cancels out.

Since the spin cancels out, neither policymaker gains from their communication. However, the disclosure reduces (compared to no disclosure) the flexibility of the central bank to react to information arriving between the intermediate date and the next policy meeting. As a result, both policymakers are worse off than if they could each commit to not using informal communication. This provides an illustration of welfare-reducing use of unattributed communication. It is analogue to the prisoners' dilemma, in which both prisoners would be better off if neither confessed (to get a reduced sentence) but both confess in equilibrium. 


\section{Figure 2}

The tug of war over market expectations: Spin reaction functions

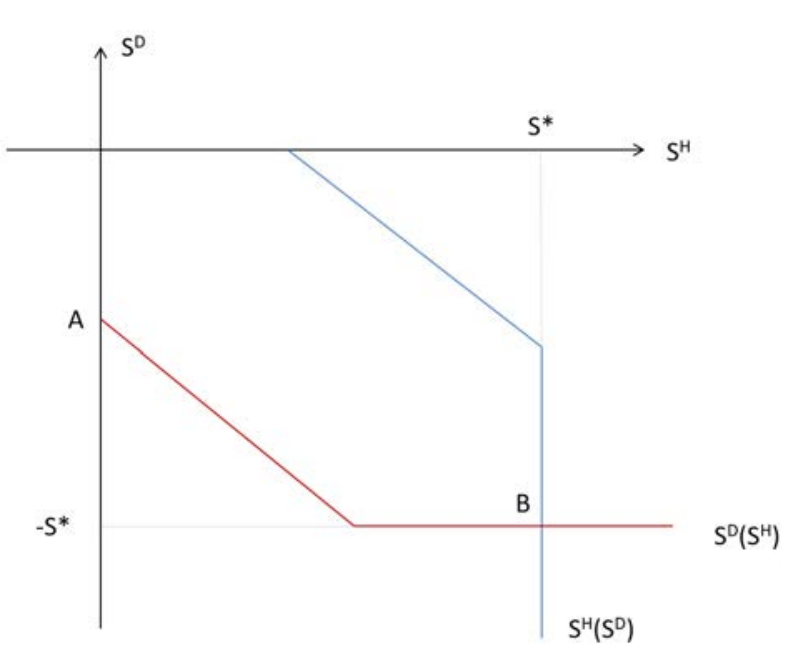

In the model described, both parties are equally able to spin, implying that spin cancels in equilibrium. One could think of cases in which the internally known information all (or mainly) favours one side, with the other side unable to counter. Two recent disclosures of ECB staff projections the day before scheduled policy announcements exemplify this.

- $\quad$ A September 11, 2019, a Reuters article titled "ECB projections to show future growth barely above 1\%: sources" illustrates a dovish leak, motivated by a desire for additional policy accommodation. It states: "Growth will be not far above 1 percent both this year and next, the figures are expected to show, underpinning the ECB's plans to approve more stimulus, the sources, who asked not to be named, told Reuters." 12

- A September 9, 2020 Bloomberg article titled "ECB Forecasts Said to Show More Confidence in Economic Outlook" illustrates a hawkish leak. It attributes information about the forecast to "euro-area officials" who "also said that in their view additional monetary support beyond the current 1.35 trillion-euro (\$1.6 trillion) emergency bond-buying program doesn't appear warranted from the current perspective". ${ }^{13}$

In these examples, those communicating may benefit in the short run by an improved bargaining position at the policy meeting, but on average over time each side gains as often as they lose. ${ }^{14}$

Harm to credibility and the decision-making process: In Vissing-Jorgensen (2019), I study FOMC transcripts back to 1948 to gain insight into whether

12 https://www.reuters.com/article/us-ecb-policy-forecasts/ecb-projections-to-show-future-growth-barelyabove-1-sources-idUSKCN1VW259

${ }^{13} \mathrm{https} / / / w w w . b l o o m b e r g . c o m / n e w s / a r t i c l e s / 2020-09-09 / e c b-f o r e c a s t s-s a i d-t o-s h o w-m o r e-c o n f i d e n c e-i n-$ economic-outlook

${ }^{14} \mathrm{An}$ interesting aspect of the game-theoretic framework is that as the policy decision nears, the temptation to disclose internal information (via unattributed communication) increases since the benefit of retaining flexibility to better react to any new information that may arrive before the decision diminishes. 
unattributed communication has other costs than lost policy-flexibility relative to nondisclosure. The Fed uses the word "leak" for non-institutionally sanctioned communication of confidential information. I document 114 FOMC documents with discussions of leaks (generally one document correspond to one FOMC meeting or conference call). The documents reveal that such communication is viewed as a threat to Fed credibility and harm the Fed's decision-making process. For example, a 2010 memo from Chairman Bernanke to the FOMC states: “'...] it damages the reputation and credibility of the institution if the outside world perceives us as using leaks and other back channels to signal to markets, to disseminate points of view, or to advance particular agendas" and "such leaks threaten the free give and take of ideas and collegiality of the FOMC as we grapple with the difficult issues we face".

In addition to leaks harming the free give and take of ideas, withholding of information to prevent leaks further damages decision quality. Meyer (2004) describes how staff used to omit information from the Greenbook for fear of leaks by policymakers. A 2014 Reuters article gives an example of information withholding at the ECB, stating that "Several ECB sources said Draghi had cut back on circulating policy papers in advance of council meetings, apparently out of concern that opponents, notably in the German Bundesbank, were leaking them to try to block or discredit decisions." ${ }^{15}$ This could materially harm the quality of decisions made. watcher newsletters whether for individual or institutional reasons

The Medley Global Advisors scandal in 2012 that led to the resignation of President Lacker from the Richmond Fed was very harmful to the Fed's reputation. It reinforced concerns about unequal access to information. When I tried to buy the Medley newsletter a few years ago, it cost $\$ 120,000 /$ year. Yes, it is easier for central bankers to convey what they want to experts at newsletters, and the newsletter can drive market expectations quickly, but so can financial newspapers.

In a time when trust in formal institutions is low, populisms is prevalent, and governments are under pressure to finance huge deficits, central bank independence cannot be taken for granted. A new paper by Bianchi, Kind and Kung (2020) documents significant drops in Fed funds futures rates around Trump tweets about the Fed. How many more Medley scandals can Fed independence take?

\footnotetext{
15 https://www.reuters.com/article/us-ecb-governors-exclusive/exclusive-central-bankers-to-challengedraghi-on-ecb-leadership-style-idUSKBNOIO1GY20141104
} 
At the ECB, President Lagarde has introduced a series of changes to limit unattributed communication driven by disagreements. A February 2020 Reuters article titled "No phones, no leaks: How Lagarde is making her mark on ECB" describes the changes. ${ }^{16}$ The change in phone use are useful and make for a good headline, but other changes are likely more important. They include the president spending more time listening to colleagues, building consensus, not front-running decisions before meetings, and showing more trust in colleagues by distributing meeting proposals up to a week in advance, not just hours before for fear of leaks.

How do these changes relate to the prisoners dilemma? Standard solutions include enforcement (in a military context, think of arms treaties with inspectors) or punishment in a repeated version of the game. The new no phones policy fits in the enforcement category but only helps for information obtained during the meetings. The consensus-building approach maps directly to the repeated game solution, since the President now has the choice to take away influence if someone leaks. This cannot work perfectly, since leakers are hard to identify. However, an improved consensus-focused culture is likely to make leaking less acceptable among colleagues who may know the identity of a leaker. While they may not formally want to reveal this, they can help impose informal sanctions. After all, many policymakers will see their influence reduced if the President goes back to a less consensusbuilding approach. Pozen (2013) describes in the US political context how leakers are disciplined informally via "shaming, shunning and exiling".

\section{References}

Bianchi, F., T. Kind, and H. Kung (2020), "Threats to Central Bank Independence: High-Frequency Identification with Twitter", working paper.

Cieslak, A., A. Morse and A. Vissing-Jorgensen (2019), "Stock Returns over the FOMC Cycle", Journal of Finance, 74, 7, 2201-2248.

Lucca, D. O. and E. Moench (2015), “The Pre-FOMC Announcement Drift”, Journal of Finance, 72, 1, 329-371.

Morse, A. and A. Vissing-Jorgensen (2020), "Information Transmission from the Federal Reserve to the Stock Market: Evidence from Governors' Calendars", working paper.

Pozen, D. E. (2013), "The Leaky Leviathan: Why the Government Condemns and Condones Unlawful Disclosures of Information", Harvard Law Review, 127, 512-635.

Vissing-Jorgensen, A. (2019), "Central Banking with Many Voices: The Communications Arms Race", Conference Proceedings, 23rd Annual Conference of the Central Bank of Chile.

${ }^{16}$ https://www.reuters.com/article/us-ecb-policy-lagarde-inisght/no-phones-no-leaks-how-lagarde-is-makingher-mark-on-ecb-idUSKBN2040NO 